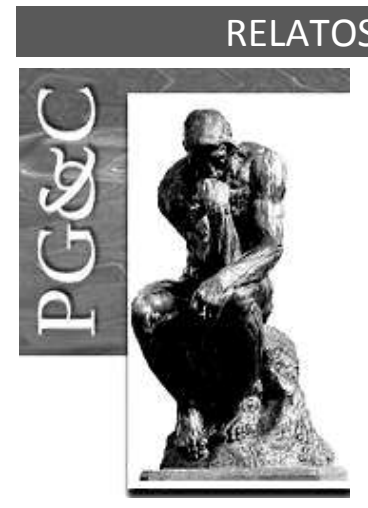

\title{
REVISTA IBERO-AMERICANA DE ESTRATÉGIA: PRODUÇÃO ACADÊMICA DE 2002 A 2015
}

\author{
Henrique César Melo Ribeiro \\ Doutor em Administração de Empresas pela Universidade Nove de Julho, \\ Brasil. Professor da Universidade Federal do Piauí, Brasil. \\ E-mail: hcmribeiro@gmail.com \\ Rosany Corrêa \\ Doutora em Administração de Empresas pela Universidade Nove de Julho, \\ Brasil. Professora da Universidade Estadual do Piauí, Brasil.
}

E-mail: rosanycorrea@hotmail.com

\begin{abstract}
Resumo
O objetivo deste estudo é investigar a representatividade e as particularidades da produção acadêmica divulgada pela Revista Ibero-Americana de Estratégia durante o período de 2002 a 2015. Metodologicamente, utilizou-se as técnicas de análise bibliométrica e sociométrica. Os principais achados foram: a rede social das Instituições de Ensino Superior apresenta-se dispersa e com baixa interação, impactando em uma alta centralidade (grau e intermediação), que é refletida por meio das instituições: Universidade Nove de Julho, Universidade de São Paulo e Fundação Getúlio Vargas de São Paulo. Dos 93 temas identificados neste artigo, oito aparecem como os mais publicados: internacionalização, estratégias, sustentabilidade, empreendedorismo, inovação, balanced scorecard, gestão ambiental e responsabilidade social. Conclui-se de maneira macro, a análise da produção científica da revista ora investigada, evidenciado dados, informações, conhecimentos e saberes contemporâneos nas nuances da Estratégia, contribuindo para melhor entender e compreender, à luz do periódico investigado, como este tema se comporta, no que tange a sua produção e colaboração científica, mediante as redes dos autores e de suas respectivas IES nativas no âmbito acadêmico brasileiro.
\end{abstract}

Palavras-chave: Periódico científico. Produção acadêmica. Estratégia. Ensino e pesquisa.

\section{IBEROAMERICAN OF STRATEGY JOURNAL: ACADEMIC PRODUCTION OF 2002 TO 2015}

\begin{abstract}
The aim of this study is to investigate the representativeness and the particularities of the academic production published by the Ibero-American Journal of Strategy during the period from 2002 to 2015. Methodologically, the techniques of bibliometric and sociometric analysis were used. The main findings were: the social network of Higher Education Institutions is dispersed and with low interaction, impacting on a high centrality (degree and intermediation), which is reflected through the institutions: Universidade Nove de Julho, University of São Paulo and Getúlio Vargas Foundation of São Paulo. Of the 93 themes identified in this article, eight appear as the most published: internationalization, strategies, sustainability, entrepreneurship, innovation, balanced scorecard, environmental management and social responsibility. The analysis of the scientific production of the journal investigated, with data, information, knowledge and contemporary knowledge in the nuances of the Strategy, is concluded in a macro way, contributing to better understand and understand, in the light of the investigated period, how this theme behaves, with regard to their production and scientific collaboration, through the networks of authors and their respective native HEIs in the Brazilian academic field.
\end{abstract}

Keywords: Scientific Journal. Academic production. Strategy. Teaching and research.

Perspectivas em Gestão \& Conhecimento, João Pessoa, v. 8, n. 1, p. 210-231, jan./abr. 2018. DOI: http://dx.doi.org/10.21714/2236-417X2018v8n1p210.

http://periodicos.ufpb.br/ojs2/index.php/pgc. ISSN: 2236-417X. Publicação sob Licença (cc) EY-NC-ND 


\section{INTRODUÇÃO}

A análise da produção acadêmica está sendo uma ferramenta utilizada com constância para se aferir, entender e compreender o nível de desenvolvimento das áreas do conhecimento científico (SARAIVA; CARRIERI, 2009). Neste contexto, ressalta-se a produção acadêmica em estratégia no Brasil, pois desde a década de 1990 vem crescendo e sido tornando recorrente na literatura acadêmica nacional (SOARES et al., 2015) atingindo assim um estágio de maturidade em comparação com outras áreas da administração (RODRIGUES FILHO, 2004), sendo também considerado, um dos temas mais complexos (RIBEIRO; COSTA; FERREIRA, 2014), porém, um dos mais estudados e ensinados, não somente no contexto nacional, mas no âmbito internacional (MARCON; BANDEIRA-DE-MELLO, 2016).

Em ato continuo contempla-se que as revistas acadêmicas têm um papel basilar na concretização de determinado campo do saber científico, tendo em vista que são meios de comunicação primordial para a divulgação e a difusão dos resultados de estudos acadêmicos (KNEIPP et al., 2013). Em outras palavras, é notório que periódicos acadêmicos abalizam os contornos de um campo do saber científico, enfatizando o que é publicado (e o que não é publicado) contribuindo para dar o norte àquilo que se entende e compreende por academia (TONELLI, 2016).

Desse modo, tendo em vista o caráter primordial das publicações na atividade de colaboração dos pesquisadores (KNEIPP et al., 2013; FERRAZ et al., 2014) e a necessidade de melhor entendimento e compreensão das particularidades da produção acadêmica dos periódicos brasileiros (RIBEIRO, 2015), sobretudo do campo da estratégia, têm-se a seguinte questão de pesquisa que norteará este estudo: Qual a representatividade e as particularidades da produção acadêmica divulgada pela Revista Ibero-Americana de Estratégia (RIAE) durante o período de 2002 a 2015. E o presente estudo possui como objetivo investigar a representatividade e as particularidades da produção acadêmica divulgada pela Revista IberoAmericana de Estratégia durante o período de 2002 a 2015.

Justifica-se investigar a representatividade e as particularidades da produção acadêmica da revista RIAE em virtude da mesma servir como veículo de publicação periódica de estudos de pesquisa teóricos e aplicados, da área de estratégia, que estudam as empresas, países, mercados e sociedade em geral (RIAE, 2016), ou seja, publica trabalhos originais e inéditos no campo da estratégia, visando contribuir para a otimização da produção e divulgação científica no campo do conhecimento da estratégia (RIAE, 2016).

A referida publicação contribui para a literatura acadêmica nacional no momento em que conduz um conhecimento dos resultados das pesquisas divulgadas pela revista RIAE, sendo este preponderante para a disseminação, difusão e a evolução do saber científico no campo da estratégia. Outra contribuição é vista no momento em que se entende e compreende-se que as publicações evidenciadas no periódico RIAE investigaram a evolução do conhecimento do campo da estratégia e que esta se relacionou, de certa forma, aos resultados de dissertações de mestrado, teses de doutorado e/ou estudos originários de grupos de pesquisa consolidados e/ou emergentes, proporcionando assim uma condição de elencar, por exemplo, os 93 temas identificados e abordados nos 294 artigos publicados.

O citado estudo está subdivido em cinco seções. A primeira seção aborda a introdução, com a justificativa, questão, objetivo e contribuição de pesquisa. A fundamentação teórica aborda a estratégia e sua produção acadêmica em seu estado da arte. A seção três esboça os procedimentos metodológicos. A análise e discussão dos resultados estão evidenciadas na seção quatro. E por fim, contemplam-se as considerações finais, junto com as conclusões, contribuições finais, limitações e sugestões para estudos futuros.

Perspectivas em Gestão \& Conhecimento, João Pessoa, v. 8, n. 1, p. 210-231, jan./abr. 2018. 


\section{ESTRATÉGIA E SUA PRODUÇÃO ACADÊMICA}

O campo da estratégia pode ser visualizado como prática organizacional (MAIA; DI SERIO; ALVES FILHO, 2015) e categorizado em pelo menos duas dimensões: a primeira dimensão é a dos estudos que são realizados, publicados e difundidos pelos pesquisadores que integram o universo da literatura acadêmico e a segunda dimensão é a da prática organizacional sob a égide dos tomadores de decisão (MACHADO-DA-SILVA; VIZEU, 2007).

Realça-se assim que a estratégia é um campo prático (WALTER; BACH; BARBOSA, 2012), realçando e entendendo que ao evidenciar que a estratégia é uma área prática, não significa a aversão ou a ojeriza à teoria e/ou à teorização, mas simplesmente manifesta que a estratégia procura aplicações e resultados que servem como calculo de performance das organizações (BERTERO; VASCONCELOS; BINDER, 2003), criando vantagem competitiva (SCHNEIDER et al., 2009).

Neste contexto, pode-se entender também que a estratégia é um processo assumido pelos gestores essencial para as tomadas de decisão (RIBEIRO et al., 2016), se caracterizando por diferentes padrões de ação, porém, estas iniciativas irão depender de como os gestores perceberam o ambiente para interagir com os atores externos (BIGNETTI; PAIVA, 2002), sendo que cada um destes atores poderá contribuir para a criação de valor para a empresa (SCHNEIDER et al., 2009).

Diante do exposto, versa-se a importância da estratégia para as empresas (CLEGG; CARTER; KORNBERGER, 2004). Isto posto, manifesta-se a estratégia empresarial, que é considerada um campo multidisciplinar que reúne contribuições de campos do conhecimento tão diversos, tais como: economia, teoria organizacional, sociologia, psicologia e ciência política (VASCONCELOS, 2002).

Diante disso, observa-se que a estratégia empresarial é uma área de expressiva importância para os estudos de gestão, tendo em vista o impacto das decisões e iniciativas estratégicas para o sucesso das organizações (PERUSSI FILHO; ESCRIVÃO FILHO, 2012). Neste panorama, tem-se e entende-se que o objetivo da estratégia empresarial é desenvolver vantagem competitiva para a empresa (ZILBER; LAZARINI, 2008).

Salienta-se que a vantagem competitiva é conquistada quando uma empresa consegue criar valor (ITO et al., 2012), num produto ou serviço que vai além do seu custo e que não pode ser simultaneamente implementado por outras organizações atuais ou potenciais. Neste sentido, entende-se que a vantagem competitiva é uma medida de competitividade, pois recomenda a posição de uma empresa em relação aos seus concorrentes ou em relação à sua posição no mercado (CONTO; ANTUNES JÚNIOR; VACCARO, 2016).

Diante do contexto, aflora-se que a estratégia competitiva é buscada pela organização a fim de que, consiga uma posição competitiva que a favoreça no mercado corporativo (BARBOSA; OLIVEIRA, 2002), então, cada empresa que compete em um determinado mercado, necessita ter uma estratégia competitiva (MEGLIORINI; GUERREIRO, 2004) e que a particularidade desta é a criação de valor para as organizações (ITO et al., 2012).

Neste sentido, compreende-se que a estratégia competitiva é feita mediante um processo decisório no qual se busca descobrir os nichos de mercado nos quais a organização poderia identificar oportunidades para ser competitiva. Sendo que tais nichos são contemplados por gaps existentes entre os aspectos competitivos presentes nos produtos e/ou serviços oferecidos pela concorrência e aqueles valorizados pelo mercado (CONTADOR, 2011).

Em suma, a estratégia é inerente ao sucesso dos negócios, seja ela qual for, exigindo, portanto, atenção tanto no mercado corporativo com a responsabilidade dos tomadores de decisão, que buscam traçar estratégias competitivas, reais e consistentes, criando valor (ITO et

Perspectivas em Gestão \& Conhecimento, João Pessoa, v. 8, n. 1, p. 210-231, jan./abr. 2018. 
al., 2012) e vantagem competitiva (CONTO; ANTUNES JÚNIOR; VACCARO, 2016), para as empresas.

Quanto também no mundo acadêmico por meio dos autores que desenvolvem suas pesquisas, publicando-as e difundindo-as sobre o tema estratégia (ROCZANSKI et al., 2010) a fim de que, seja traçado, a posteriori, seu mapeamento no contexto científico internacional e especialmente, como é o foco deste estudo, no âmbito nacional. Diante disso, segue algumas publicações, em seu estado da arte, sobre a produção científica do tema em estratégia, a fim de que possam ajudar nas futuras discussões dos resultados do citado estudo.

Walter, Bach e Barbosa (2012) analisaram a estrutura de relacionamento dos atores sociais envolvidos no desenvolvimento da abordagem de estratégia como prática no Brasil e no exterior no período entre 1996 e 2011. Os pesquisadores observaram que a abordagem da estratégia como prática se destaca principalmente na Inglaterra, visto que as instituições e autores mais prolíficos e mais citados são desse país. Quanto ao Brasil, não se identificaram autores ou instituições proeminentes, bem como se verificou que a maior parte das instituições está localizada nas regiões Sudeste e Sul.

Walter e Bach (2013) analisaram o papel desempenhado pelos novos autores no desenvolvimento da produção científica brasileira na área de estratégia durante o período de 1997-2010. As autoras observaram um grau elevado de centralidade e a existência de grupos de pesquisas coesos nas redes de cooperação. Destacaram que os temas mais estudados foram a internacionalização e desempenho organizacional.

Walter et al. (2013) analisaram as redes de cooperação entre pesquisadores da área de estratégia no período de 1997 a 2010. Os principais resultados de acordo com os autores foram: a instituição que mais publicou na área foi a Universidade de São Paulo (USP); e verificaram que houve uma evolução na estrutura de relacionamentos das redes de coautoria uma vez que os períodos configuraram-se com um aumento no volume de pesquisadores e das instituições de ensino superior.

Watanabe, Gomes e Hoffmann (2013) identificaram como ocorre a cooperação entre grupos de pesquisa em estratégia no Brasil, durante o período de 2005 a 2011. Os autores verificaram a existências de redes esparsas, com predomínio de relações fracas e estrutura do tipo centro-periferia; os grupos mais centrais são os que mais se envolvem com instituições internacionais; os grupos centrais também são os que mais publicam, sugerindo que a conectividade tende a potencializar a produção científica em estratégia.

Soares et al. (2015) analisa a participação feminina na produção científica sobre estratégia usando a base de dados o Scientific Periodicals Electronic Library (SPELL) e dentro os anos de 2003 a 2013. Os autores constataram que a participação feminina nos estudos em estratégia é menor se comparada ao gênero masculino, havendo, todavia, ampliação desta participação no decorrer do período, mantendo-se estável. Identificaram também diferenças regionais relevantes, sendo o Sul e o Sudeste as regiões mais profícuas em volume de publicação. Verificaram a valorização das abordagens tradicionais da estratégia, principalmente das escolas prescritivas da estratégia.

Ferreira et al. (2015) descreveram a evolução dos estudos sobre Estratégia no setor público. Para tanto, fez-se uma sistematização e uma breve avaliação da produção científica sobre estratégia no setor público brasileiro. Os pesquisadores apontam que se pesquisa pouco o tema estratégia no setor público; e que esse setor ainda não utiliza os instrumentos fornecidos pela área de estratégia.

Andrade et al. (2016) analisaram a produção acadêmica sobre estratégia como prática (strategy as practice), buscando compreender o perfil e tendências do campo a partir do texto seminal de Whittington, R., Strategy as Practice. Os pesquisadores constataram que a estratégia como prática é centrada em textos com ênfase nas categorias analíticas 'poder' e

Perspectivas em Gestão \& Conhecimento, João Pessoa, v. 8, n. 1, p. 210-231, jan./abr. 2018. 
'instituições' e nos pontos de inflexão é verificada a importância da 'virada narrativa', bem como dos 'discursos estratégicos' e do 'sensemaking'.

Marcon e Bandeira-de-Mello (2016) analisaram nove anos (2003-2011) da pesquisa em estratégia no Brasil publicada nos principais periódicos de administração do país, e nos anais do EnANPAD (Encontro Nacional da Associação Nacional de Pós-Graduação em Administração), na divisão de Estratégia em Organizações (ESO), e do 3Es. Os autores observaram uma tendência de crescimento da pesquisa nos temas sobre negócios internacionais e sobre sustentabilidade socioambiental e ética corporativa.

As pesquisas evidenciadas anteriormente mostram como o tema estratégia é amplo e com isso, aflora-se sua importância no desenvolvimento da área do conhecimento Administração. As publicações contempladas nesta seção esboçam características que fazem robustecer a estratégia na literatura científica internacional, especialmente nacional, manifestando que é um tema maduro e legitimado no contexto acadêmico, ajudando de maneira alargada sua essência e preponderância no cenário empresarial.

As publicações versadas nesta seção disponibilizam dados e informações que ajudam a entender a importância da revista RIAE no contexto acadêmico brasileiro, pois, através de seu foco e escopo retrata com imparcialidade e qualidade a difusão do conhecimento em estratégia, mediante, suas redes de atores (autores e IES) e temas, que ajudam a entender e compreender como é fundamental o assunto estratégia para tomadores de decisão e acadêmicos da área.

Neste panorama, vislumbra-se a contribuição do citado estudo para a academia, pois, torna público informações interessantes e contemporâneas sobre o tema estratégia, à luz da RIAE, uma das mais importantes revistas científicas que tem o foco e escopo voltado a estratégia, possibilitando com isso uma visão macro, de como o referido tema esta sendo pesquisado, publicado, difundido e disseminado no Brasil, em especial, no que se refere as temáticas que alicerçam, embasam e dão direção a estratégia de maneira robusta e alargada, propiciando consequentemente sua maior socialização e fomento na academia.

\section{PROCEDIMENTOS METODOLÓGICOS}

O objetivo do estudo é investigar a representatividade e as particularidades da produção acadêmica divulgada pela Revista Ibero-Americana de Estratégia durante o período de 2002 a 2015. Para tanto, utilizou-se as técnicas de análise bibliométrica e de rede social (sociometria) (RIBEIRO; CIRANI; FREITAS, 2013; SILVA, 2014).

A bibliometria é o estudo das propriedades quantitativas de produção, socialização e uso da informação publicada (MENDES; URBINA, 2015) em livros, relatórios e em artigos (RIBEIRO et al., 2014). Ela também quantifica, analisa e investiga a produção intelectual acadêmica dos temas (RAMOS-RODRÍGUEZ; RUÍZ-NAVARRO, 2004), sendo, portanto, adaptada ao objetivo desta pesquisa. Justifica-se o uso das técnicas de análise bibliométrica por ela conseguir mapear um período longitudinal alargado de tempo, auxiliando, assim, a identificar dados e informações fundamentais aos temas e/ou áreas do conhecimento investigadas (NERUR, RASHEED; NATARAJAN, 2008).

Estudos bibliométricos sobre a produção acadêmica de periódicos científicos nacionais foram já realizados em Administração, são eles: Batistella, Bonacim e Martins (2008), Roczanski et al. (2010), Francisco (2011), Kneipp et al. (2013), Portulhak (2014), Ribeiro (2015), Ribeiro et al. (2016). Realçam-se também os estudos internacionais dos autores: RamosRodríguez e Ruíz-Navarro (2004), Biemans, Griffin e Moenaert (2007), Robertson (2008), Calabretta, Durisin e Ogliengo (2011), Shilbury (2011), e Kim, Chelladurai e Kim (2015). Observa-se que analisar a produção científica de periódicos está sendo recorrente e vem em

Perspectivas em Gestão \& Conhecimento, João Pessoa, v. 8, n. 1, p. 210-231, jan./abr. 2018. 
crescimento na literatura acadêmica global, surgindo mais uma justificativa para a realização da citada pesquisa.

É importante ressaltar que a análise bibliométrica é alicerçada em três Leis, são elas: Lotka, Bradford e Zipf (SANTOS; KOBASHI, 2009). A Lei de Lotka expressa a produtividade dos autores; a Lei de Bradford elucida a produtividade dos periódicos científicos; e a Lei de Zipf expressa a medição da frequência do surgimento das palavras em textos científicos (FAVORETO; AMÂNCIO-VIEIRA; SHIMADA, 2014).

Neste contexto, frisa-se que a bibliometria utiliza métodos de análise de redes sociais (FRANCISCO, 2011). A rede social é um conjunto de atores, que se encontram conectado entre si por meio de um conjunto de relações sociais de tipo específico (FIALHO, 2014). Neste contexto, versa-se que a institucionalização da análise de redes sociais evoluiu muito nos últimos anos, em virtude da conquista de espaços universitários, bem como na formação de grupos de pesquisa (FIALHO, 2014).

$\mathrm{Na}$ análise de rede social existe a medida de centralidade, que para está técnica de análise é fundamental (RIBEIRO, 2016). Diante disso, conceitua-se centralidade como sendo uma medida de acessibilidade de um ator para com os demais atores de uma rede social. Ressalta-se que a centralidade, além de mensurar a acessibilidade de um ator, aferi o número de nortes de comunicação que passam por ele (RÉGIS; BASTOS; DIAS, 2007).

Em suma, utiliza-se a noção de centralidade, para evidenciar que quanto mais centrais os atores, mais importantes são os mesmos em uma rede social. Neste sentido, enfoca-se que três medidas são mais frequentemente utilizadas para esse tipo de ajuizamento: centralidade de grau (degree), centralidade de intermediação (betweenness) e centralidade de proximidade (closeness) (ROSSONI; GUARIDO FILHO, 2007). Para este estudo, somente as duas primeiras serão enfatizadas.

A centralidade de grau é definida pelo número de laços adjacentes que um ator possui com outros atores em uma rede social, permitindo uma estimativa da atividade local dos atores. Em relação a centralidade de intermediação, ela mensura a dependência de atores não adjacentes de outros que atuam como uma espécie de ponte para a concretização da interação entre eles. Diante disso, quanto maior o nível de centralidade, maior o controle potencial de um ator sobre outros atores que dele dependem para executar a influência mútua (ROSSONI; GUARIDO FILHO, 2007).

A coleta de dados se fez por meio uma pesquisa documental, que se elucida por escolher, organizar, discutir e interpretar informações que se compreendiam em estado bruto e espalhadas (BEUREN; LONGARAY, 2003). A pesquisa documental procurou informações dos trabalhos, mediante o site (http://www.revistaiberoamericana.org/ojs/index.php/ibero) da Revista Ibero-Americana de Estratégia (RIAE).

O universo da pesquisa é composto por 294 artigos publicados no período 2002 a 2015. Foi finalizada a mensuração de todos os 294 estudos. Tal aferição focou na identificação de informações que compõem cada artigo (autores, IES e temas) e que foram de suma importância para que se conseguisse responder a questão de pesquisa desta investigação. Estes elementos também foram fundamentais para a criação e geração das figuras e das tabelas visualizadas nesta pesquisa.

Diante do contexto, efetivou-se a investigação do citado paper, por meio dos seguintes indicadores bibliométricos e sociométricos: (I) autores; (II) IES; (III) redes de coautoria (degree); (IV) redes de coautoria (betweenness); (V) rede social das IES (degree); (VI) rede social das IES (betweenness); e (VII) temas abordados. Sendo que os indicadores: I, II e VII focam na bibliometria, e as variáveis III, IV, V e VI enfocam na rede social (DALCOL et al., 2014; FERRAZ et al., 2014; SILVA, 2014). Enfatizam-se que as análises sociométricas do presente estudo, se deu por meio de cálculos realizados através do software (ferramenta) UCINET 6 e, as visualizações das redes sociais foram aferidas utilizando o software NetDraw for Windows, e, a análise 
bibliométrica dos indicadores deu-se mediante mensurações realizadas através do software Microsoft Excel 2007.

\section{ANÁLISE E DISCUSSÃO DOS RESULTADOS}

Esta seção enfatiza a análise e discussão dos resultados dos 294 artigos identificados.

\subsection{Autores}

A Tabela 1 evidencia os 630 autores identificados neste trabalho, colocando em ênfase os 11 mais profícuos.

Tabela 1 - Autores

\begin{tabular}{|c|c|c|c|c|c|c|c|c|c|c|c|c|c|c|c|}
\hline \multirow{2}{*}{ Autores/Anos } & 0 & 0 & 0 & 0 & 0 & 0 & 0 & 0 & 1 & 1 & 1 & 1 & 1 & 1 & Tota \\
\hline & 2 & 3 & 4 & 5 & 6 & 7 & 8 & 9 & 0 & 1 & 2 & 3 & 4 & 5 & 1 \\
\hline Emerson Antônio Maccari & & & & 1 & & & 1 & 1 & 1 & & & 1 & 1 & 1 & 7 \\
\hline Carlos Alberto Gonçalves & & & & & & & & 1 & 1 & 1 & 1 & 1 & & 1 & 6 \\
\hline Maurício Fernandes Pereira & & & & & & & & 1 & 1 & 1 & 1 & 1 & 1 & & 6 \\
\hline Carlos Ricardo Rossetto & & & & & & & & 1 & 1 & & 1 & 1 & 1 & & 5 \\
\hline Miguel Arantes Normanha Filho & & 1 & 1 & 1 & 2 & & & & & & & & & & 5 \\
\hline Alexandre Marino Costa & & & & & & & & & 1 & 1 & & 1 & 1 & & 4 \\
\hline Dirceu da Silva & & & & & & 1 & & 1 & & 1 & & & & 1 & 4 \\
\hline Elizabeth Kyoko Wada & & & & & & & & & & 1 & 1 & 1 & 1 & & 4 \\
\hline João Maurício Gama Boaventura & & & & & & & & 1 & 1 & 1 & & 1 & & & 4 \\
\hline $\begin{array}{l}\text { Sérgio Henrique Arruda Cavalcante } \\
\text { Forte }\end{array}$ & & & & & & & & & 1 & & 1 & & 1 & 1 & 4 \\
\hline Miguel Eduardo Moreno Añez & & & & & & & & 1 & & 1 & 1 & 1 & & & 4 \\
\hline 20 autores publicaram 3 artigos & & & & & & & & & & & & & & & \\
\hline 69 autores publicaram 2 artigos & & & & & & & & & & & & & & & \\
\hline 530 autores publicaram 1 artigo & & & & & & & & & & & & & & & \\
\hline
\end{tabular}

Fonte: Dados da pesquisa (2016)

Emerson Antônio Maccari surge como autor mais profícuo neste estudo, ao publicar sete artigos, entretanto, estas publicações não foram em anos diretos e sim intercalados. Ao contrário dos autores Carlos Alberto Gonçalves e Maurício Fernandes Pereira que divulgaram seus estudos em períodos diretos, ajudando assim em seus respectivos destaques como pesquisadores prolíferos também neste trabalho, com ambos com seis divulgações.

É interessante ressaltar também os articulistas Miguel Arantes Normanha Filho e Elizabeth Kyoko Wada que também divulgaram seus trabalhos em anos diretos, ocasionando seus bons desempenhos na publicação de artigos na revista ora analisada.

De maneira geral, 11 autores publicaram de quatro a sete estudos; 20 pesquisadores publicaram três artigos; 69 estudiosos divulgaram dois artigos cada; e a grande maioria, ou seja, 530 articulistas divulgaram um artigo cada. Tal resultado remete a Lei de Lotka no que tange a produtividade dos autores, pois, versa que poucos pesquisadores publicam muito e muitos pesquisadores manifestam de maneira menos acentuada suas investigações (RIBEIRO, 2016). 


\subsection{As Instituições de Ensino Superior (IES)}

A Tabela 2 mostra as 181 IES identificadas neste trabalho, colocando em evidencia as 11 instituições que mais publicaram.

Tabela 2 - IES

\begin{tabular}{|c|c|c|c|c|c|c|c|c|c|c|c|c|c|c|c|c|}
\hline IES/Anos & 0 & $\begin{array}{l}0 \\
3\end{array}$ & 0 & $\begin{array}{l}0 \\
5\end{array}$ & 0 & 0 & 0 & 0 & 1 & 1 & 1 & $\begin{array}{l}1 \\
3\end{array}$ & 1 & 1 & Tota & $\%$ \\
\hline Uninove & 6 & 8 & 7 & $\begin{array}{l}1 \\
0\end{array}$ & $\begin{array}{l}1 \\
1\end{array}$ & 5 & 2 & 3 & 3 & 4 & 4 & 6 & 4 & 7 & 80 & $\begin{array}{c}27,21 \\
\%\end{array}$ \\
\hline USP & & 1 & & 1 & 2 & 2 & 5 & 4 & 5 & 3 & 3 & 7 & 5 & 2 & 40 & $\begin{array}{c}13,61 \\
\%\end{array}$ \\
\hline Univali & & & & & & & & 2 & 4 & 1 & 2 & 3 & 1 & & 13 & $4,42 \%$ \\
\hline FGV (SP) & & & & & 2 & 2 & 1 & & 3 & & 1 & 1 & & 2 & 12 & $4,08 \%$ \\
\hline UFSC & & & & & & & 1 & 1 & 1 & 1 & 1 & 3 & 2 & 2 & 12 & $4,08 \%$ \\
\hline UNIP & & & & 1 & 1 & 2 & & 1 & 1 & 1 & & 2 & & 1 & 10 & $3,40 \%$ \\
\hline UPM & & 2 & 2 & 1 & & 1 & 1 & 1 & & & & & 1 & 1 & 10 & $3,40 \%$ \\
\hline UFRN & & & & & & 1 & 1 & 1 & & 2 & 1 & 1 & & 1 & 8 & $2,72 \%$ \\
\hline PUC (PR) & & & & & & & 2 & & & & & 2 & 2 & 1 & 7 & $2,38 \%$ \\
\hline UFMG & & & & & & & & 1 & 1 & & 2 & 2 & & 1 & 7 & $2,38 \%$ \\
\hline UFRGS & & & & & & & & & & 1 & 2 & 2 & & 2 & 7 & $2,38 \%$ \\
\hline $\begin{array}{l}21 \text { IES publicaram de } 4 \text { a } 6 \\
\text { artigos } \\
31 \text { IES publicaram de } 3 \text { a } 2 \\
\text { artigos }\end{array}$ & & & & & & & & & & & & & & & & \\
\hline 118 IES publicaram 1 artigo & & & & & & & & & & & & & & & & \\
\hline
\end{tabular}

Fonte: Dados da pesquisa (2016)

A Universidade Nove de Julho (Uninove) se destaca neste estudo ao ter publicado 80 artigos de 2002 a 2015. Tal fato, é em virtude da revista ora analisada ser pertencente a citada IES, e, portanto, impactar diretamente em sua produtividade no referido periódico. A quantidade de artigos publicados pela Uninove é maior nos primeiros cinco anos de vida da RIAE. Tal fato pode ser explicado porque, os periódicos científicos, e isso não é inerente apenas a RIAE, no inicio de suas publicações, costumam publicar e divulgar estudos de pesquisadores da IES em que a revista é vinculada, influenciando com isso em sua produção de trabalhos científicos.

Isto posto, percebe-se que a quantidade de artigos publicados pela Uninove declina a partir de 2007, podendo ser em decorrência de sua preocupação em minimizar a endogênia e também por abrir possibilidade de maior integração de outros pesquisadores e de suas respectivas IES na produção científica da RIAE. Tal ação, possibilitou o acréscimo de outros estudiosos na geração do conhecimento, por meio de seus estudos, na revista RIAE, e consequentemente as instituições os quais tem vinculo agregando valor, fomentando o foco e escopo da RIAE no cenário acadêmico nacional em estratégia.

Outra IES que ficou em evidencia neste estudo foi a USP. Mas, de maneira geral, seu destaque não é somente nesta revista, visto que, a USP por sua importância e realce na produção acadêmica de estudos, fica em foco em outros estudos, sejam eles com enfoque na produção acadêmica de periódicos (RIBEIRO et al., 2016) como também, em estudos que versam sobre temas da área de administração (RIBEIRO, 2016), em especial na área de estratégia (WALTER et al., 2013) 
Em seguida surgem as IES: Universidade do Vale do Itajaí (Univali), Fundação Getulio Vargas (FGV-SP), Universidade Federal de Santa Catarina (UFSC), Universidade Paulista (UNIP), Universidade Presbiteriana Mackenzie (UPM), Universidade Federal do Rio Grande do Norte (UFRN), Pontifícia Universidade Católica (PUC-PR), Universidade Federal de Minas Gerais (UFMG) e Universidade Federal do Rio Grande do Sul (UFRGS), que publicaram respectivamente, $13,12,12,10,10$, oito, sete, sete e sete estudos. Diante disso, nota-se que há o predomínio de IES das regiões Sudeste e Sul, sendo consideradas, para este estudo, as mais profícuas em número de artigos publicados. Tal dado é apoiado de maneira similar na pesquisa de Walter, Bach e Barbosa (2012) e Soares et al. (2015).

Em suma, versa-se que 21 IES publicaram de quatro a seis artigos; 31 instituições divulgaram de dois a três trabalhos; e a grande maioria, ou seja, 118 IES evidenciaram apenas um estudo cada. Tal achado vai ao encontro do que foi contemplado nesta seção, ou seja, de que a Uninove preocupa-se em robustecer e alargar o conhecimento da área de estratégia, que é o foco da RIAE, e para isso, divulga e publica investigações de instituições nacionais e também internacionais, criando assim, a possibilidade de fomento de temas (como pode ser visto na Tabela 3 deste artigo) que alicerçam e norteiam a estratégia, impactando consequentemente no maior desenvolvimento e difusão do campo do saber administração.

\subsection{Redes de coautoria (degree)}

A coautoria em publicações científicas pode ser considerada indicador preponderante, pois é utilizado para caracterizar as redes de cooperação entre autores (WATANABE; GOMES; HOFFMANN, 2013; FERRAZ et al., 2014; SILVA, 2014). Diante disso, na Figura 1 visualiza-se a rede de coautoria dos 630 pesquisadores identificados neste estudo, enfatizando a centralidade de grau.

Figura 1 - Redes de coautoria (degree)

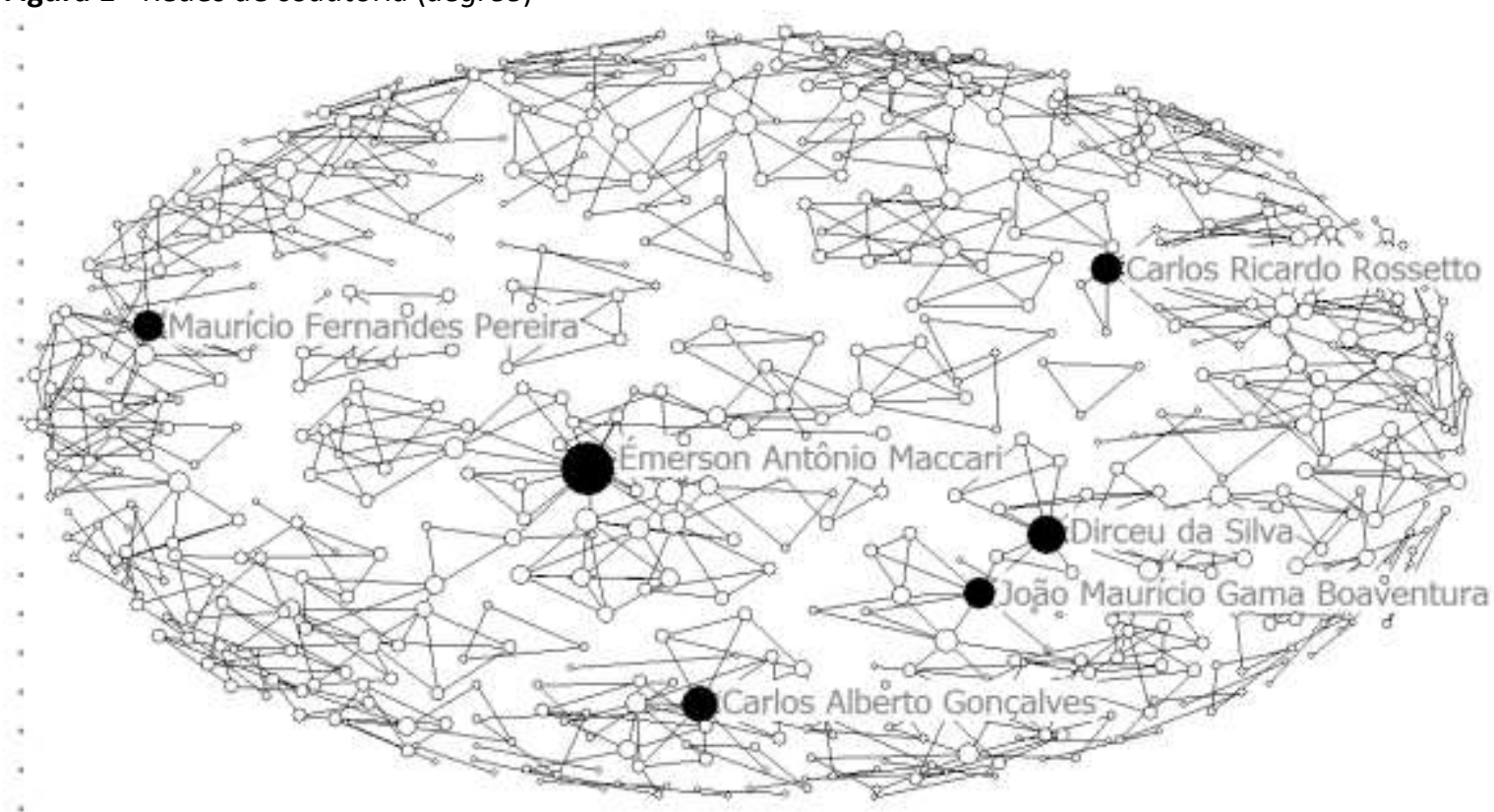

Fonte: Dados da pesquisa (2016) 
Os autores Emerson Antonio Maccari, Carlos Alberto Gonçalves, Maurício Fernandes Pereira, Carlos Ricardo Rossetto, Dirceu da Silva e João Maurício Gama Boaventura, foram os mais centrais neste estudo. Estes acadêmicos que se destacaram nesta seção, surgem também entre os 11 mais profícuos (Tabela 1), o que confirma e mostra que estes autores são os mais importantes na rede social (ROSSONI; GUARIDO FILHO, 2007) que se apresenta.

Diante do exposto, mesmo sendo sob à luz da produção acadêmica da revista RIAE, observa-se a existência de vários grupos de estudos, mas, apesar disso, a referida rede de coautoria tem um nível realçado de centralidade. Tal informação, é sustentada no estudo de Walter e Bach (2013). Este elevado grau de centralidade, influência na baixa densidade de rede que foi mensurada em 0,0042 , o que equivale a dizer que apenas $0,42 \%$ das interações estão sendo realizadas de maneira efetiva.

Neste panorama, entende-se que a rede de coautoria desta investigação é esparsa, com ascendência de relações fracas (WATANABE; GOMES; HOFFMANN, 2013), o que evidencia pouca interação entre os pesquisadores envolvidos nos estudos (RIBEIRO; CIRANI; FREITAS, 2013). Este achado é confirmado na pesquisa de Francisco (2011), no tocante a análise da produtividade da revista RAE-eletrônica.

\subsection{Redes de coautoria (betweenness)}

Já a Figura 2 evidencia novamente a rede de coautoria, contudo, agora enfatizando a centralidade de intermediação.

Figura 2 - Redes de coautoria (betweenness)

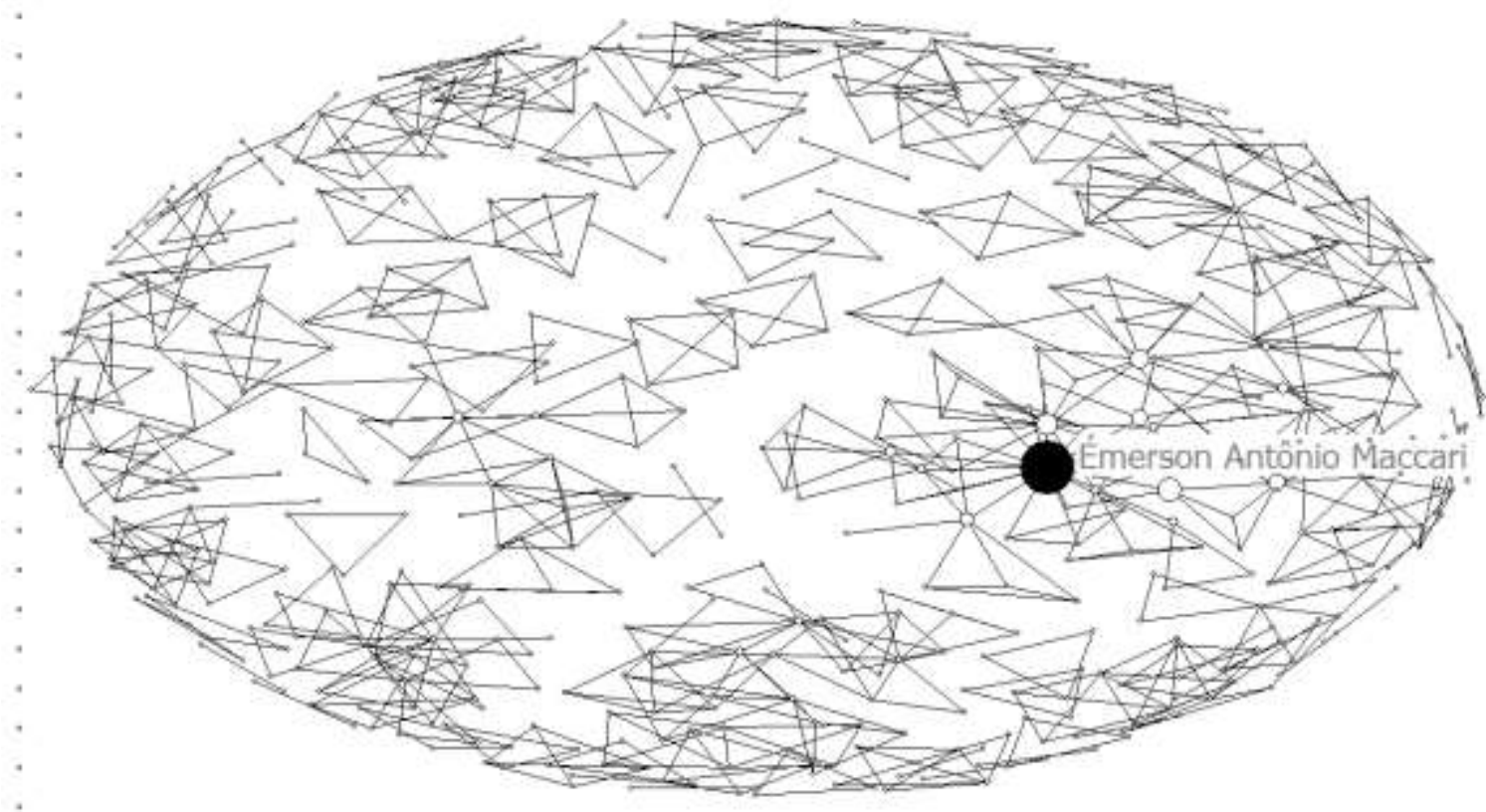

Fonte: Dados da pesquisa (2016)

Nesta seção, destaca-se o acadêmico Emerson Antônio Maccari como o mais central em relação a intermediação. Entende-se com isso que o determinado pesquisador, atua como uma ponte para interação com outros autores, sendo que quanto maior o nível de sua centralidade de intermediação, maior o controle potencial que o mencionado pesquisador tem sobre os outros acadêmicos que dele dependem para executar a interação (ROSSONI; GUARIDO FILHO, 2007), na rede de coautoria deste estudo. 
Remete-se a dizer que quanto maior a conectividade entre os autores, maior será o potencial de difusão, fomento e socialização da produção científica do tema estratégia (WATANABE; GOMES; HOFFMANN, 2013), mesmo sendo sob a ótica da revista ora investigada.

\subsection{Rede social das IES (degree)}

Em todo campo do saber, há uma rede de cooperação entre os autores e instituições de pesquisa (WALTER et al., 2013; DALCOL et al., 2014). Neste contexto, aflora-se a seguir, por meio da Figura 3, a rede social das 181 IES identificadas nesta investigação, colocando em foco as IES com maior centralidade de grau.

Figura 3 - Rede social das IES (degree)

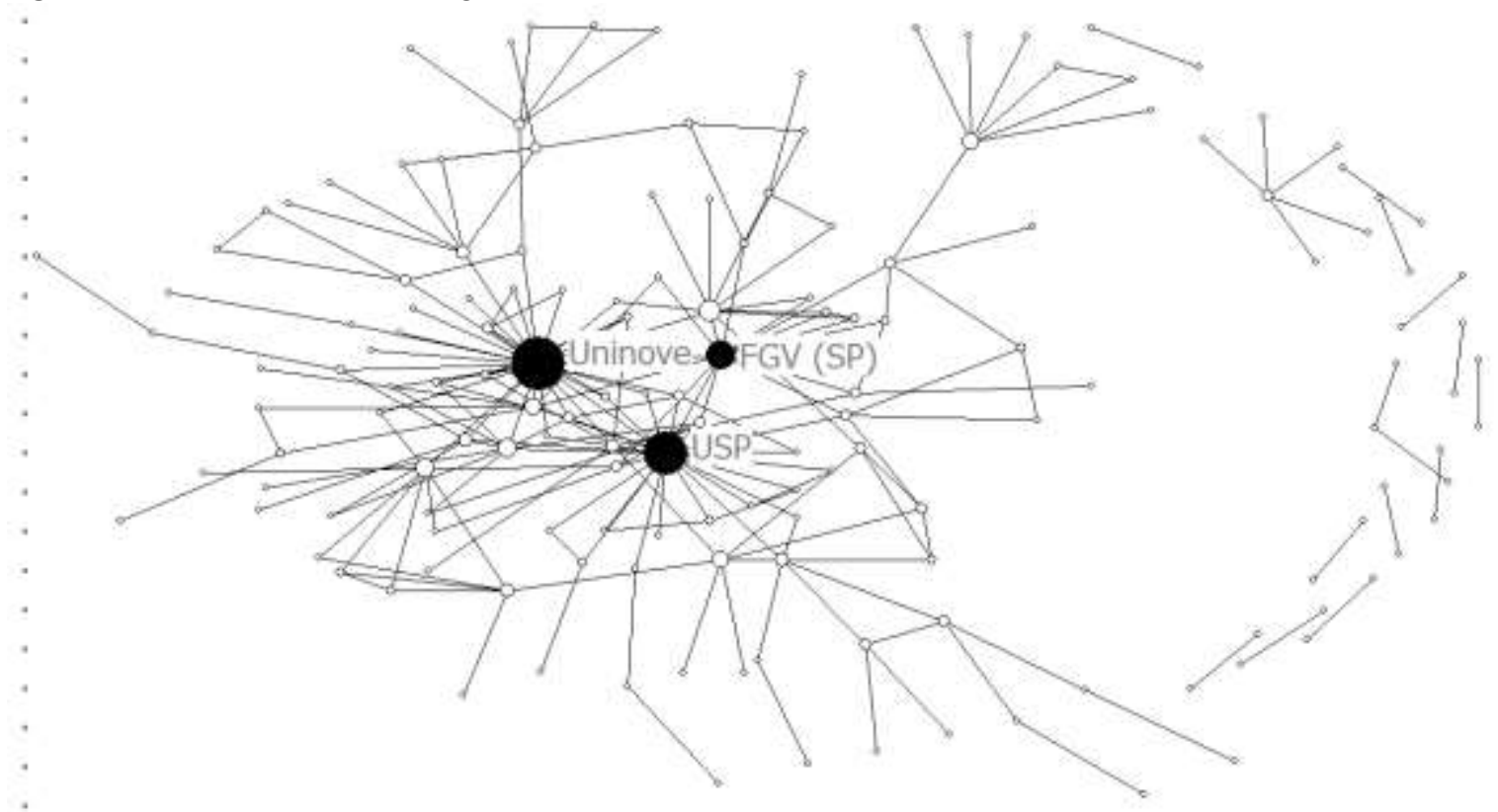

Fonte: Dados da pesquisa (2016)

As IES Uninove, USP e FGV (SP) conseguiram se destacar no que tange a centralidade de grau, confirmando o que foi visto na Tabela 2 deste estudo, a qual mostra o realce destas IES na produção de estudos na revista ora investigada. Estes achados são vistos de maneira semelhante no estudo dos acadêmicos Ribeiro, Cirani e Freitas (2013), ao colocarem em evidencia as IES Uninove, USP e FGV (SP) como as mais centrais, no tocante a análise da produção científica da Revista de Administração e Inovação (RAI). Salienta-se que na época em que foi realizada a mencionada investigação, a RAl era atrelada a Uninove, porém, hoje, tem vinculo com a USP.

\subsection{Rede social das IES (betweenness)}

A Figura 4 versa novamente sobre a rede social das IES identificadas neste trabalho, entretanto, agora, coloca em enfoque as IES com maior centralidade de intermediação. 
Figura 4 - Rede social das IES (betweenness)

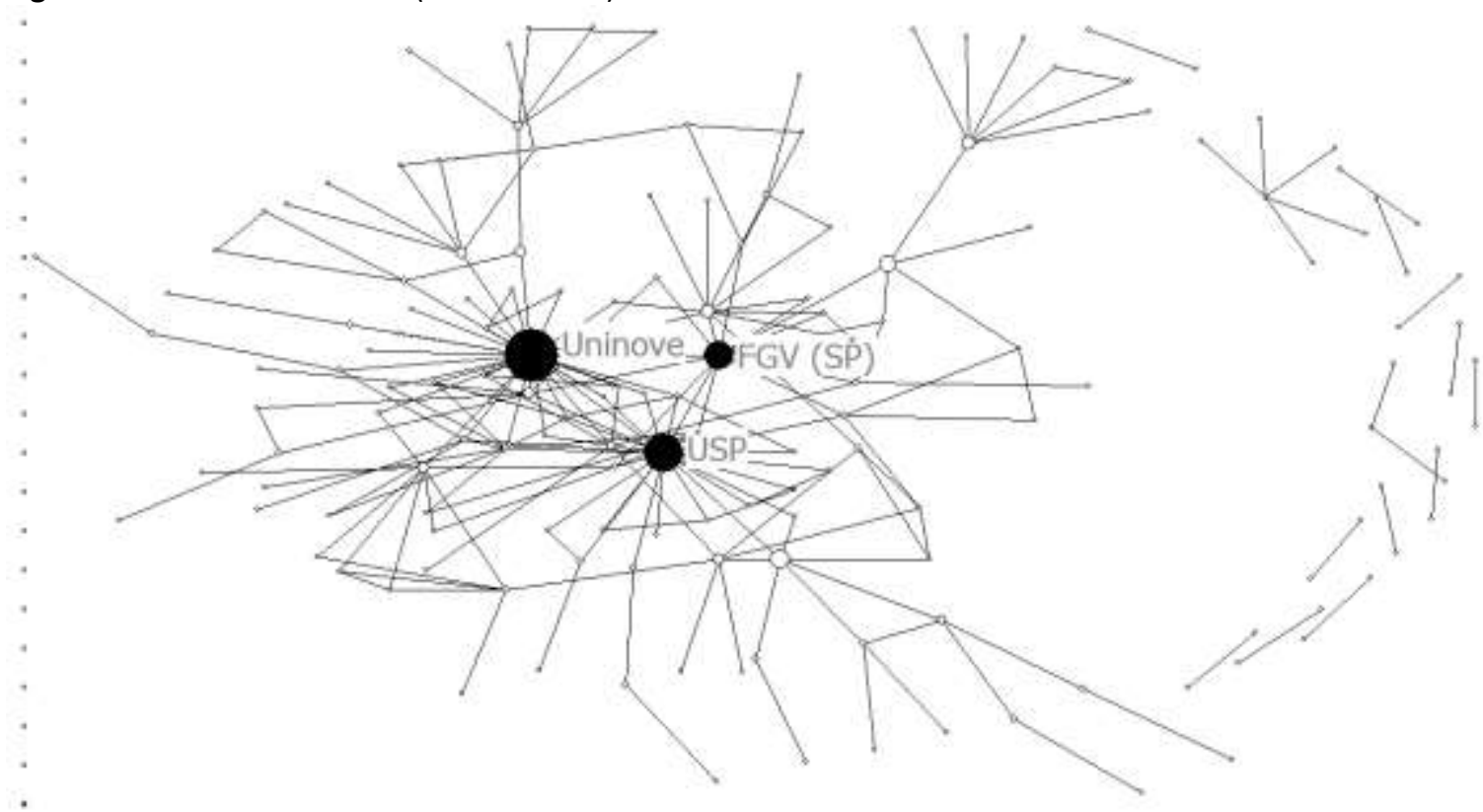

Fonte: Dados da pesquisa (2016)

E como ocorrerá na centralidade de grau, também na centralidade de intermediação, destacam-se as IES: Uninove, USP e FGV (SP). Os achados contemplados nesta seção e na anterior nos leva e nos faz entender e compreender que a visualização da estrutura da rede social das IES como um todo pode esclarecer uma série de pontos relativos ao campo do conhecimento estratégia (ROSSONI; GUARIDO FILHO, 2007) sob a ótica da revista RIAE, contudo, não se pode negar que as IES que se destacam (Uninove, USP e FGV-SP), possam apresentar papel central e preponderante na constituição, fomento, difusão e socialização do conhecimento científico da área de estratégia no Brasil.

\subsection{Temas abordados}

A Tabela 3 evidencia os 93 temas identificados e abordados neste estudo, durante os 14 anos de publicação acadêmica da revista RIAE.

Tabela 3: Temas abordados

\begin{tabular}{|c|c|c|c|c|c|c|c|c|c|c|c|c|c|c|c|}
\hline Temas/Anos & 02 & 03 & 04 & 05 & 06 & 07 & 08 & 09 & 10 & 11 & 12 & 13 & 14 & 15 & Total \\
\hline Internacionalização & & & & & 1 & & & 1 & 2 & 5 & 4 & 2 & 1 & 2 & 18 \\
\hline Estratégias & 1 & & & & & & 1 & 1 & 1 & & & 5 & 5 & 3 & 17 \\
\hline Sustentabilidade & & & & & 1 & 4 & 3 & & & & & 2 & 2 & & 12 \\
\hline Empreendedorismo & & & & & & & 1 & 1 & & 1 & & 2 & 4 & 2 & 11 \\
\hline Inovação & & 1 & & & & 1 & & & & & 2 & 2 & 2 & 2 & 10 \\
\hline Balanced Scorecard & & & & & & & & & 1 & 2 & 1 & 1 & 2 & 2 & 9 \\
\hline Gestão Ambiental & 1 & & & & & 2 & 3 & & & & 1 & & 1 & & 8 \\
\hline Responsabilidade Social & & 1 & 1 & & 4 & 1 & & & & & & & & 1 & 8 \\
\hline Estratégia Empresarial & & 1 & & & & & & 1 & 2 & 1 & 2 & & & & 7 \\
\hline Formação de Estratégias & & & & & & & & & 1 & 3 & & 1 & & 2 & 7 \\
\hline Marketing & 1 & 1 & & & & 1 & & & & & 1 & 2 & & 1 & 7 \\
\hline Negócios Internacionais & & 1 & 1 & & 1 & 1 & & & 1 & 1 & & 1 & & & 7 \\
\hline
\end{tabular}

Perspectivas em Gestão \& Conhecimento, João Pessoa, v. 8, n. 1, p. 210-231, jan./abr. 2018. 
Stakeholders

Vantagem Competitiva

Competitividade

Tecnologia da Informação

Aprendizagem Organizacional

Clusters

Gestão de Pessoas

Gestão Estratégica

Alianças Estratégicas

APL

Cenários

Cultura Organizacional

Governança Corporativa

Planejamento Estratégico

Terceiro Setor

Turismo

VBR

Capacidades Dinâmicas

Economia 1

Inovação Tecnológica

Marketing de Serviços

Responsabilidade Social Empresarial

Alta Administração

Capital Intelectual

Clima Organizacional

Decisões Estratégicas

Desempenho Organizacional

Ensino e Pesquisa

Cooperação

Ética

Franchising

Gerenciamento de Projetos

Gestão Hospitalar

Implementação de Estratégia

Marketing Social

Mudança Organizacional

Privatização

QVT

Responsabilidade Socioambiental

Alinhamento Estratégico

Ambiente Organizacional

Análise SWOT

Avaliação de Desempenho

Competências

Comportamento Estratégico

Consultoria

Coopetição

Custos de Transação

Empresa Familiar

Empresas Multinacionais

\begin{tabular}{|c|c|c|c|c|c|c|c|c|c|c|c|c|c|c|}
\hline & & & & & & & & 1 & 1 & 1 & 2 & 1 & 1 & 7 \\
\hline & & & & & 1 & & 1 & 3 & & & 1 & & 1 & 7 \\
\hline & & 1 & & 1 & & & 1 & 1 & 1 & 1 & & & & 6 \\
\hline \multirow[t]{15}{*}{1} & 1 & & & & & 2 & 1 & & & & & 1 & & 6 \\
\hline & 1 & & & & & & 1 & & 1 & 1 & 1 & & & 5 \\
\hline & & & & 1 & & & & 1 & 1 & & 1 & 1 & & 5 \\
\hline & & & & & & & & 1 & & 1 & 1 & & & 5 \\
\hline & & & & & & & & 1 & & 1 & 3 & & & 5 \\
\hline & & & 1 & & & 1 & 1 & & & & & & 1 & 4 \\
\hline & & & & & & 1 & & 1 & & 1 & & & 1 & 4 \\
\hline & & & & & & & & 1 & & 2 & 1 & & & 4 \\
\hline & 1 & 2 & & & & & 1 & & & & & & & 4 \\
\hline & & & & 1 & & & 1 & & & & 1 & & 1 & 4 \\
\hline & & & & & & & & 1 & & 3 & & & & 4 \\
\hline & 1 & & 1 & 1 & 1 & & & & & & & & & 4 \\
\hline & & & 2 & 1 & 1 & & & & & & & & & 4 \\
\hline & & & & & & & 1 & & & 1 & & 2 & & 4 \\
\hline & & & & & & & & & & & & 2 & 1 & 3 \\
\hline \multirow[t]{14}{*}{1} & 1 & & & 1 & & & & & & & & & & 3 \\
\hline & & & 1 & & & & & & 1 & & & 1 & & 3 \\
\hline & & 1 & & & 1 & 1 & & & & & & & & 3 \\
\hline & & 1 & & & 1 & & & & & & & & 1 & 3 \\
\hline & & & & & & & 1 & & & & & & 1 & 2 \\
\hline & 1 & & & & & & & & & & 1 & & & 2 \\
\hline & & & 1 & & 1 & & & & & & & & & 2 \\
\hline & & & & & & & 1 & 1 & & & & & & 2 \\
\hline & & & & & & & & & & & 1 & 1 & & 2 \\
\hline & & & & & & & & & & & & 1 & 1 & 2 \\
\hline & & & & & & 1 & & & 1 & & & & & 2 \\
\hline & & & & 1 & & & & & & & & & 1 & 2 \\
\hline & & & & & & & & & & 1 & & 1 & & 2 \\
\hline & & & & & & & & & & 1 & 1 & & & 2 \\
\hline \multirow{3}{*}{\multicolumn{2}{|c|}{1}} & & & 1 & & & & & & & & & & 2 \\
\hline & & & & & & & & & & & 1 & 1 & & 2 \\
\hline & & 1 & & & & & & & & & & & 1 & 2 \\
\hline & 1 & & 1 & & & & & & & & & & & 2 \\
\hline & & & & 1 & & & & & & & 1 & & & 2 \\
\hline & & & & 2 & & & & & & & & & & 2 \\
\hline & & & & 1 & & & & & & & 1 & & & 2 \\
\hline & & & & & & & & & 1 & & & & & 1 \\
\hline & & & & & & & & & & & & 1 & & 1 \\
\hline & & & & & & & & 1 & & & & & & 1 \\
\hline & & & & & & & & & & & & & 1 & 1 \\
\hline & & & & & & & & & & 1 & & & & 1 \\
\hline & & & & & & & & & 1 & & & & & 1 \\
\hline & & & & & & & & & & 1 & & & & 1 \\
\hline & & & & & & & & & & & 1 & & & 1 \\
\hline & & & & & & & & & & 1 & & & & 1 \\
\hline & & & & & & & & & 1 & & & & & 1 \\
\hline & & & & & & & & & & & 1 & & & 1 \\
\hline
\end{tabular}

Perspectivas em Gestão \& Conhecimento, João Pessoa, v. 8, n. 1, p. 210-231, jan./abr. 2018. 


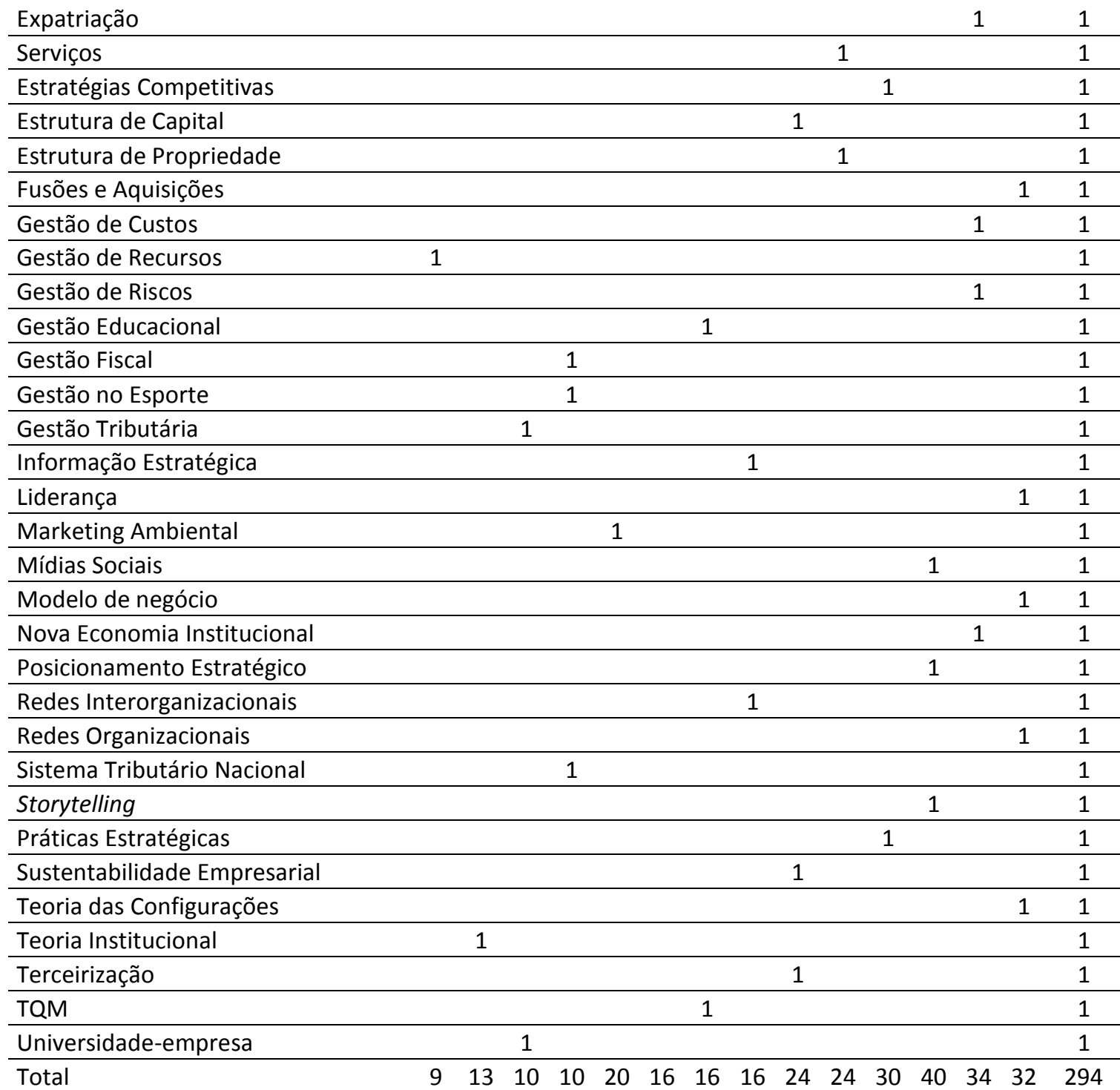

Fonte: Dados da pesquisa (2016)

O tema internacionalização acabou sendo o mais divulgado, aparecendo em destaque em 18 artigos. Ressalta-se que suas publicações, começaram a ter maior difusão, a partir de 2009. Seu destaque neste estudo deve-se ao fato de ser considerado fator preponderante de mudança estratégica nas organizações (MACHADO-DA-SILVA; FERNANDES, 1999), proporcionando as empresas tornarem-se mais competitivas não somente no ambiente interno, como, sobretudo no cenário internacional, potencializando suas fontes de vantagem competitiva (SILVA; CRESPAM; SCHERER, 2013). Walter e Bach (2013) em sua pesquisa colocam em ênfase a internacionalização como um dos temas mais estudados pelos autores.

A temática estratégia ficou na segunda colocação deste estudo, com 17 artigos publicados. Seu realce está diretamente relacionado com o foco e o escopo da revista ora analisada, que é a difusão do conhecimento em estratégia (RIAE, 2016). De maneira geral, as estratégias são essenciais para o sucesso dos negócios, e é por isso, que as organizações buscam abalizar estratégias competitivas que criem valor (ITO et al., 2012) e que gerem vantagem competitiva (CONTO; ANTUNES JÚNIOR; VACCARO, 2016).

Realça-se agora a temática sustentabilidade, que nesta investigação surgiu em realce em 12 publicações, em especial, durante os anos de 2006 a 2008. Sua evidencia, é em virtude, 
de ser considerado um tema relevante (PEÇANHA; IIZUKA, 2014), recorrente, em crescimento nas pesquisas acadêmicas, e que, portanto, atingiu seu amadurecimento na área de administração no Brasil, tendo isso, influência direta no mundo corporativo (DE LUCA et al., 2014). Em sua investigação, os acadêmicos Marcon e Bandeira-de-Mello (2016), ressaltam também o tema sustentabilidade, colocando-o em evidencia.

Empreendedorismo se apresenta como uma estratégia empresarial (SILVEIRA et al., 2010) e diante disso, foi outro assunto que se destacou neste estudo ao ser difundido em 11 publicações. Sendo assim, ressalva-se que, apesar do tema empreendedorismo, no meio acadêmico nacional ser emergente, seu entendimento e compreensão, são preponderantes para o campo do conhecimento administração (BORBA; HOELTGEBAUM; SILVEIRA, 2011).

O tema inovação foi responsável pela divulgação de dez estudos. Seu realce dá-se por sua abrangência e universalidade de sua aplicabilidade em uma variedade de campos do saber e temáticas (PINHEIRO et al., 2014), como por exemplo a área de administração (BRANDÃO; BRUNO-FARIA, 2013) e a estratégia (TORRES; SILVA, 2014) respectivamente, que colocam a inovação tanto como instrumento, quanto um comportamento e também como diretriz (PINHEIRO et al., 2014).

O Balanced Scorecard vem a seguir com nove publicações. Sua proeminência decorre de sua importância como modelo de desempenho (HÉKIS, 2004), que traduz a estratégia de uma empresa em objetivos, indicadores, metas e ações de fácil entendimento e compreensão pelos gestores e colaboradores (QUEIROZ; QUEIROZ; HÉKIS, 2011), e que sua aplicação de maneira recorrente nas organizações, proporcionou seu aperfeiçoamento para uma metodologia de gestão estratégica (GALLON et al., 2008).

Ressaltam-se também as temáticas gestão ambiental e responsabilidade social que foram publicadas oito vezes cada uma. Diante do exposto, ressalva-se que o destaque do tema gestão ambiental é em virtude da preocupação e consequentemente do interesse crescente tanto de acadêmicos como de tomadores de decisão, que buscam entender e compreender e, assim, melhor abordar, cuidar e controlar as questões ambientais (TRIERWEILLER et al., 2013). $E$ a responsabilidade social, que é considerada um conjunto de atividades éticas colocadas em prática por agentes sociais, cidadãos, órgãos públicos e privados, com ou sem fins lucrativos, voltadas para o desenvolvimento sustentável da sociedade (SINAY et al., 2013, p. 66). Isto posto, versa-se e observa-se a interação entre a gestão ambiental e a responsabilidade social (MACEDO; FREITAS; GUERRA, 2013).

Contempla-se também que 21 temas foram publicados de quatro a sete vezes; 22 temas foram divulgados entre duas e três vezes; e a grande maioria, isto é, 42 assuntos, foram evidenciados apenas uma vez. Isto mostra, em especial, no que se refere aos temas publicados apenas uma vez, uma oportunidade de novas publicações, com o foco na área de estratégia, possibilitando com isso, um maior desenvolvimento de temáticas ainda pouco abordadas e, ou seja, embrionárias, no contexto acadêmico nacional, sob a ótica da revista RIAE, impactando no crescimento e alargamento de assuntos voltados a estratégia e posteriormente na evolução da área do conhecimento administração.

\section{CONSIDERAÇÕES FINAIS}

O objetivo deste estudo foi investigar a representatividade e as particularidades da produção acadêmica divulgada pela Revista Ibero-Americana de Estratégia durante o período de 2002 a 2015. Para tanto, utilizou-se as técnicas de análise bibliométrica e sociométrica em 294 artigos identificados.

Os resultados revelam informações interessantes, contemporâneas que ajudam a melhor compreender o tema estratégia no contexto literário acadêmico nacional. É fato, que fora analisada apenas uma revista científica nacional, contudo, também é fato que esta foca a

Perspectivas em Gestão \& Conhecimento, João Pessoa, v. 8, n. 1, p. 210-231, jan./abr. 2018. 
difusão do conhecimento em estratégia (RIAE, 2016) e que já tem certa vivencia na publicação, difusão e disseminação do saber do citado tema, e, que, portanto, elenca credenciais para que seja investigada e usada como meio de pesquisa e referencial para futuros estudos da produção cientifica em estratégia nacional e quiçá internacional.

Os achados vistos neste estudo esboçam informações que levam a entender que o tema estratégia é maduro no contexto acadêmico nacional, porém, é possível desenvolve-lo ainda mais, como por exemplo, fomentando a densidade das redes sociais dos atores (autores e IES) analisados aqui, pois, por meio de uma maior densidade, a interação das redes de coautoria e consequentemente das IES tendem a otimizar, criando com isso a possibilidade de surgimento de novos grupos de estudos, consolidação dos já existentes e/ou expansão destes.

Uma maior densidade das redes sociais dos atores viabilizaria de maneira direta, na amplitude e no crescimento de temas que versam diretamente sobre a estratégia, impactando concomitantemente no crescimento de assuntos embrionários, na maturidade de temáticas em emergência e na legitimação de temas já maduros, influenciando diretamente, como já havia sido reportado, na área de estratégia e, simultaneamente no campo do conhecimento de administração.

A contribuição desta pesquisa é, além de analisar a produção acadêmica da revista RIAE, foi também manifestar o atual estágio da produção científica e do formato de configuração relacional da pesquisa do campo da estratégia, à luz da revista RIAE, auxiliando discussões que admitam um melhor entendimento e compreensão por parte do editor, leitores e pesquisadores e Programas de Pós-Graduações stricto sensu (FERREIRA; PINTO; BELFORT, 2016), da área do conhecimento estratégia. A investigação do campo do saber estratégia permite discutir, comparar, refletir e analisar sobre o desenvolvimento dos temas que compõem o conceito de estratégia para a citada área do saber sob a ótica da revista RIAE.

A limitação do referido estudo foi justamente investigar apenas um periódico científico nacional com foco em estratégia, contudo, ressalta-se que a questão e o objetivo da pesquisa foram respondidos e alcançados respectivamente. Isto posto, versa-se a seguir algumas sugestões para estudos futuros: (1) fazer uma pesquisa similar a esta, utilizando para investigação dois ou mais periódicos científicos nacionais de foco e escopo igual (estratégia), possibilitando assim criar maior valor ao conhecimento do assunto estratégia; (2) fazer investigação entre duas revistas científicas que enfatizam a estratégia, uma brasileira e uma estrangeira, para realizar uma comparação de como está sendo difundido e socializado o conhecimento em estratégia no Brasil e em escala global; (3) desenvolver mais as análises de redes sociais, como por exemplo, enfatizando a centralidade de aproximação e a análise das cocitações; (4) aperfeiçoar a análise bibliométrica enfocando, por exemplo a análise das referências; e (5) fazer uma análise mais aprofundada, quem sabe usando o método de análise de conteúdo nos temas identificados e abordados nesta pesquisa.

\section{REFERÊNCIAS}

ANDRADE, L. F. S. et al. Desvelando o campo da estratégia como prática e suas relações. Revista Ibero-Americana de Estratégia, v. 15, n. 1, p. 06-26, 2016.

BARBOSA, M. de L. de A.; OLIVEIRA, L. M. B. de. O marketing interno como estratégia de gerenciamento dos recursos humanos em hotéis: um estudo de caso na região metropolitana do Recife. Organizações \& Sociedade, v. 9, n. 24, p. 91-101, 2002. 
BATISTELLA, F. D.; BONACIM, C. A. G.; MARTINS, G. de A. Contrastando as produções da Revista Contabilidade \& Finanças (FEA-USP) e Revista Base (Unisinos). Revista de Educação e Pesquisa em Contabilidade, v. 2, n. 3, p. 84-101, 2008.

BERTERO, C. O.; VASCONCELOS, F. C. de; BINDER, M. P. Estratégia empresarial: a produção científica brasileira entre 1991 e 2002. Revista de Administração de Empresas, v. 43, n. 4, p. 48-62, 2003.

BIEMANS, W.; GRIFFIN, A.; MOENAERT, R. Twenty years of the Journal of Product Innovation Management: History, participants, and knowledge stock and flows. Journal of Product Innovation Management, v. 24, n. 3, p. 193-213, 2007.

BIGNETTI, L. P.; PAIVA, E. L. Ora (direis) ouvir estrelas!: estudo das citações de autores de estratégia na produção acadêmica brasileira. Revista de Administração Contemporânea, v. 6 , n. 1, p. 105-125, 2002.

BORBA, M. L. de; HOELTGEBAUM, M.; SILVEIRA, A. A produção científica em empreendedorismo: análise do Academy of Management Meeting: 1954-2005. Revista de Administração Mackenzie, v. 12, n. 2, p. 169-206, 2011.

BRANDÃO, S. M.; BRUNO-FARIA, M. de F. Inovação no setor público: análise da produção científica em periódicos nacionais e internacionais da área de administração. Revista de Administração Pública, v. 47, n. 1, p. 227-248, 2013.

CALABRETTA, G.; DURISIN, B.; OGLIENGO, M. Uncovering the intellectual structure of research in business ethics: a journey through the history, the classics, and the pillars of Journal of Business Ethics. Journal of Business Ethics, v. 104, n. 4, p. 499-524, 2011.

CLEGG, S. R.; CARTER, C.; KORNBERGER, M. A "máquina estratégica": fundamentos epistemológicos e desenvolvimentos em curso. Revista de Administração de Empresas, v. 44, n. 4, p. 21-31, 2004.

CONTADOR, J. L. Metodologia para a formulação da estratégia competitiva de manufatura: um enfoque quantitativo. Revista de Administração e Contabilidade da Unisinos, v. 8, n. 4, 2011.

CONTO, S. M. de; ANTUNES JÚNIOR, J. A. V.; VACCARO, G. L. R. A inovação como fator de vantagem competitiva: estudo de uma cooperativa produtora de suco e vinho orgânicos. Gestão \& Produção, p. 1-11, 2016.

DALCOL, C. C.; SILUK, J. C. M.; NEUENFELDT JÚNIOR, Á. L.; SOLIMAN, M. Mensuração da competitividade em instituições de ensino superior privadas com base nas redes sociais digitais. Perspectivas em Gestão \& Conhecimento, v. 4, Número Especial, p. 96-108, 2014.

DE LUCA, M. M. M.; CARDOSO, V. I. da C.; VASCONCELOS, A. C. de; PONTES, A. B. Análise da produção científica referente à temática de sustentabilidade em pesquisas da administração. Administração: Ensino e Pesquisa, v. 15, n. 3, p. 469-500, 2014.

FAVORETO, R. L.; AMÂNCIO-VIEIRA, S. F.; SHIMADA, A. T. A produção intelectual em RBV: uma incursão bibliométrica nos principais periódicos nacionais. Revista Brasileira de Estratégia, $v$. 7, n. 1, p. 37-55, 2014.

Perspectivas em Gestão \& Conhecimento, João Pessoa, v. 8, n. 1, p. 210-231, jan./abr. 2018. 
FERRAZ, R. R. N.; QUONIAM, L. M.; MACCARI, E. A.; SILVEIRA, V. O. da. Análise e gestão de análise de redes de colaboração entre pesquisadores de programas de pós-graduação stricto sensu com a utilização da ferramenta computacional scriptlattes. Perspectivas em Gestão \& Conhecimento, v. 4, Número Especial, p. 133-147, 2014.

FERREIRA, M. P.; PINTO, C. F.; BELFORT, A. C. O que é uma boa revisão de artigo em administração? Revista Eletrônica de Estratégia \& Negócios, v. 9, n. 2, p. 87-105, 2016.

FERREIRA, V. da. R. S.; NAJBERG, E.; PORTO, R. B.; SOUSA, M. de M.; BARBOSA, N. B. Pesquisa sobre estratégia no setor público brasileiro: avaliação da produção científica no período 2007 2011. Revista Contemporânea de Economia e Gestão, v. 13, n. 1, p. 85-104, 2015.

FIALHO, J. M. R. Análise de redes sociais: princípios, linguagem e estratégias de ação na gestão do conhecimento. Perspectivas em Gestão \& Conhecimento, v. 4, Edição Especial, p. 09-26, 2014.

FRANCISCO, E. de R. RAE-eletrônica: exploração do acervo à luz da bibliometria, geoanálise e redes sociais. Revista de Administração de Empresas, v. 51, n. 3, p. 280-306, 2011.

GALLON, A. V.; NASCIMENTO, S. do; ENSSLIN, S. R.; ENSSLIN, L.; DUTRA, A. Mapeamento das ferramentas gerenciais para avaliação de desempenho disseminadas em pesquisas da área de engenharia. Revista P\&D em Engenharia de Produção, v. 7, p. 53-72, 2008.

HÉKIS, H. R. Balanced Scorecard: proposta de indicadores para monitorar e avaliar projetos pedagógicos dos cursos de graduação: o caso da faculdade Estácio de Sá de Santa Catarina. Tese (Doutorado em Engenharia de Produção), UFSC, Florianópolis, 2004, 221 pg.

ITO, N. C. et al. Valor e vantagem competitiva: buscando definições, relações e repercussões. Revista de Administração Contemporânea, v. 16, n. 2, p. 290-307, 2012.

KIM, A. C.; CHELLADURAI, P.; KIM, Y. K. Scholarly thrusts in the Journal of Sport Management: citation analysis. Global Sport Business Journal, v. 3, n. 1, p. 1-23, 2015.

KNEIPP, J. M.; ROSA, L. A. B. da; BICHUETI, R. S.; POZZER, R. H. P.; SCHUCH JÚNIOR, V. F. Análise bibliométrica da produção científica da Revista de Administração da UFSM: em busca de novas perspectivas e desafios. Revista de Administração da UFSM, v. 6, n. 2, p. 443-458, 2013.

MACEDO, C. V. P. de; FREITAS, A. A. F. de; GUERRA, D. de S. A scale for measuring the importance of socio-environmental approach in business schools. Revista de Administração Mackenzie, v. 14, n. 1, p. 75-97, 2013.

MACHADO-DA-SILVA, C. L.; FERNANDES, B. H. R. O Impacto da internacionalização nos esquemas interpretativos dos dirigentes do banco Bamerindus. Revista de Administração de Empresas, v. 39, n. 1, p. 14-24, 1999.

MACHADO-DA-SILVA, C. L.; VIZEU, F. Análise institucional de práticas formais de estratégia. Revista de Administração de Empresas, v. 47, n. 4, p. 89-100, 2007. 
MAIA, J. L.; DI SERIO, L. C.; ALVES FILHO, A. G. Pesquisa bibliométrica em estratégia como prática: resultados exploratórios e comparação de fontes. Revista Eletrônica Sistemas \& Gestão, v. 10, n. 4, p. 654-669, 2015.

MARCON, R.; BANDEIRA-DE-MELLO, R. Estratégia em organizações: a produção científica brasileira entre 2003 e 2011. Revista Alcance, v. 23, n. 2, p. 127-141, 2016.

MEGLIORINI, E.; GUERREIRO, R. A percepção dos gestores sobre quanto a fatores competitivos nas empresas produtoras de bens de capital sob encomenda: um estudo exploratório. Revista de Administração e Contabilidade da Unisinos, v. 1, n. 2, p. 05-14, 2004.

MENDES, L.; URBINA, L. M. S. Análise sobre a produção acadêmica brasileira em comunidades de prática. Revista de Administração Contemporânea, v. 19, Edição Especial, p. 305-327, 2015.

NERUR, S. P.; RASHEED, A. A.; NATARAJAN, V. The intellectual structure of the strategic management field: an author co-citation analysis. Strategic Management Journal, v. 29, p. 319-336, 2008.

PEÇANHA, R. S.; IIZUKA, E. S. Análise da Produção Científica Brasileira Sobre Sustentabilidade Entre os Anos de 2008 a 2011. Revista de Gestão Ambiental e Sustentabilidade, v. 3, n. 1, p. 01-17, 2014.

PERUSSI FILHO, S.; ESCRIVÃO FILHO, E. Processo de criação de estratégia em pequenas empresas de base tecnológica: um modelo de fases evolutivas para o setor médicoodontológico. Gestão \& Produção, v. 19, n. 1, p. 173-188, 2012.

PINHEIRO, R. G.; SANTOS, I. C. dos; MAIA, C.; FERNANDES, B. Á. O. F. A produção científica sobre inovação: análise da base SciELO no período de 2005 a 2012. Estudos Tecnológicos em Engenharia, v. 10, n. 1, p. 36-48, 2014.

PORTULHAK, H. Revista de Contabilidade e Controladoria (RC\&C): análise dos cinco primeiros anos de publicação (2009-2013). Revista de Educação e Pesquisa em Contabilidade, v. 8, n. 4, p. 403-419, 2014.

QUEIROZ, F. C. B. P.; QUEIROZ, J. V.; HÉKIS, H. R. Gestão estratégica e financeira das instituições de ensino superior: um estudo de caso. Iberoamerican Journal of Industrial Engineering, v. 3, n. 1, p. 98-117, 2011.

RAMOS-RODRÍGUEZ, A. R.; RUÍZ-NAVARRO, J. Changes in the intellectual structure of strategic management research: a bibliometric study of the strategic management journal, 1980-2000. Strategic Management Journal, v. 25, p. 981-1004, 2004.

RÉGIS, H. P.; BASTOS, A. V. B.; DIAS, S. M. R. C. Redes sociais informais: análise das redes de amizade, de informação e de confiança em incubadoras de base tecnológica no Recife. Revista Psicologia Organizações e Trabalho, v. 7, n. 1, p. 31-56, 2007.

Revista Ibero-Americana de Estratégia - RIAE. Foco e escopo. Disponível em: http://www.revistaiberoamericana.org/ojs/index.php/ibero/about/editorialPolicies\#focusAnd Scope. Acesso em: 29 ago.2016. 
RIBEIRO, H. C. M.; CIRANI, C. B. S.; FREITAS, E. J. da S. M. de. Análise da produção cientifica da Revista de Administração e Inovação. Revista de Administração e Inovação, v. 10, n. 4, p. 208228, 2013.

RIBEIRO, H. C. M. et al. 35 anos de publicações acadêmicas da revista de administração da USP. Revista Ambiente Contábil, v. 8, n. 1, p. 294-322, 2016.

RIBEIRO, H. C. M.; COSTA, B. K.; FERREIRA, M. A. S. P. V.; SERRA, B. P. de C. Produção científica sobre os temas governança corporativa e stakeholders em periódicos internacionais. Contabilidade, Gestão e Governança, v. 17, n. 1, p. 95-114, 2014.

RIBEIRO, H. C. M.; COSTA, B. K.; FERREIRA, M. A. S. P. V. Produção acadêmica dos temas estratégia e governança corporativa. Revista de Administração FACES, v. 13, n. 3, p. 27-46, 2014.

RIBEIRO, H. C. M. Particularidades da produção acadêmica publicada na Revista de Administração e Contabilidade da Unisinos no período de 2004 a 2014. Revista Contabilidade Vista e Revista, v. 26, n. 3, p. 80-105, 2015.

RIBEIRO, H. C. M. Teoria dos stakeholders: um estudo bibliométrico de sua produção acadêmica divulgada nos periódicos nacionais de 1999 a 2013. Revista Contemporânea de Economia e Gestão, v. 14, n. 1, p. 163-192, 2016.

RIBEIRO, I.; SERRA, F. A. R.; FERREIRA, M. P.; SERRA, B. P. de C. Relações teóricas e conceituais em tomada de decisão estratégica. Revista Eletrônica de Estratégia \& Negócios, v. 9, n. 2, p. 57-84, 2016.

ROBERTSON, C. J. An analysis of 10 years of business ethics research in Strategic Management Journal: 1996-2005. Journal of Business Ethics, v. 80, p. 745-753, 2008.

ROCZANSKI, C. R. M.; TOSTA, K. C. B. T.; ALMEIDA, M. I. R. de; PEREIRA, M. F.; MELO, P. A. de. O Estado da arte em estratégia na Revista de Administração Contemporânea: um estudo bibliométrico. Revista Economia \& Gestão, v. 10, n. 24, p. 28-47, 2010.

RODRIGUES FILHO, J. Um estudo da produção acadêmica em administração estratégica no brasil na terminologia de Habermas. RAE eletrônica, v. 3, n. 2, p. 1-16, 2004.

ROSSONI, L.; GUARIDO FILHO, E. R. Cooperação interinstitucional no campo da pesquisa em estratégia. Revista de Administração de Empresas, v. 47, n. 4, p. 74-88, 2007.

SANTOS, R. N. M. dos; KOBASHI, N. Y. Bibliometria, cientometria, infometria: conceitos e aplicações. Ciência da Informação, v. 2, n. 1, p. 155-172, 2009.

SARAIVA, E. V.; CARRIERI, A. de P. Citações e não citações na produção acadêmica de estratégia no Brasil: uma reflexão crítica. Revista de Administração da USP, v. 44, n. 2, p. 158166, 2009.

SCHNEIDER, A. B.; CARNEIRO, M. L.; SERRA, F. A. R.; FERREIRA, M. P. Estratégia competitiva: Michael Porter 30 anos depois. Revista de Administração da UFSM, v. 2, n. 2, p. 298-326, 2009.

Perspectivas em Gestão \& Conhecimento, João Pessoa, v. 8, n. 1, p. 210-231, jan./abr. 2018. 
SHILBURY, D. A bibliometric analysis of four sport management journals. Sport Management Review, v. 14, p. 434-452, 2011.

SILVA, A. K. A. da. A dinâmica das redes sociais e as redes de coautoria. Perspectivas em Gestão \& Conhecimento, v. 4, Número Especial, p. 27-47, 2014.

SILVA, V. A. da; CRESPAM, C. C.; SCHERER, F. L. Performance exportadora: uma análise da produção científica brasileira. Revista Eletrônica de Negócios Internacionais, v. 8, n. 2, p. 22 39, 2013.

SILVEIRA, A.; ROPELATO, M.; VIEIRA, S. S.; NASCIMENTO, S. do. Empreendedorismo: produção científica na base Scielo 2004-2008. Revista de Administração da FACES, v. 9, n. 3, p. 13-32, 2010.

SINAY, M. C. F. de; DALBEM, M. C.; I. A.; VIEIRA, J. de M. Ensino e pesquisa em gestão ambiental nos programas brasileiros de pós-graduação em administração. Revista de Administração Mackenzie, v. 14, n. 3, p. 55-82, 2013.

SOARES, M. de N. M.; LESSA, B. S.; CABRAL, A. C. A.; PESSOA, M. N. M.; SANTOS, S. M. A participação feminina nos estudos sobre estratégia. Revista Raunp, v. 7, n. 1, p. 25-37, 2015.

TONELLI, M. J. RAE: desafios para o futuro. Revista de Administração de Empresas, v. 56, n. 2, 2016.

TORRES, L. F. P.; SILVA, F. C. L. da. A inovação nas empresas de Caruaru-PE. International Journal of Innovation, v. 2, n. 2, p. 142-159, 2014.

TRIERWEILlER, A. C.; CAMPOS, L. M. de S.; CARVALHO, D. N. de; SANTOS, T. H. S. dos; BORNIA, A. C.; PEIXE, B. C. S. Gestão ambiental: levantamento da produção científica brasileira em periódicos de Engenharia de Produção. Produção, v. 24, n. 2, p. 435-450, 2013.

VASCONCELOS, F. C. de. Estratégia empresarial. Revista de Administração de Empresas, v. 42, n. 2, p. 120-120, 2002.

WALTER, S. A.; BACH, T. M.; BARBOSA, F. Estratégia como prática: análise longitudinal por meio de bibliometria e sociometria. Revista Brasileira de Estratégia, v. 5, n. 3, p. 307-323, 2012.

WALTER, S. A.; BACH, T. M. LANZA, B. B. B.; SATO, K. H. Publicação científica na área de estratégia do Enanpad e do 3Es: de 1997 a 2010. Revista Ibero-Americana de Estratégia, v. 12, n. 2, p. 69-104, 2013.

WALTER, S. A.; BACH, T. M. Inserção de pesquisadores entrantes na área de estratégia: análise das relações de autoria e temas estudados no período de 1997-2010. Revista Eletrônica de Administração, v. 74, n. 1, p. 165-191, 2013.

WATANABE, E. A.; GOMES, A. O.; HOFFMANN, V. E. Cooperação entre grupos de pesquisa em estratégia no Brasil. Revista Ibero-Americana de Estratégia, v. 12, n. 1, p. 84-106, 2013.

Perspectivas em Gestão \& Conhecimento, João Pessoa, v. 8, n. 1, p. 210-231, jan./abr. 2018. 
ZILBER, M. A.; LAZARINI, L. C. Estratégias competitivas na área da saúde no Brasil: um estudo exploratório. Revista de Administração Contemporânea, v. 12, n. 1, p. 131-154, 2008. 